\title{
The performance of ultra-lightweight foamed concrete incorporating nanosilica
}

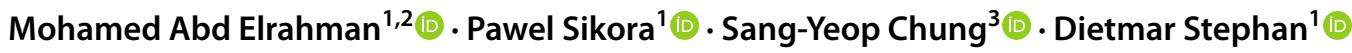

Received: 20 July 2020 / Revised: 4 October 2020 / Accepted: 16 April 2021 / Published online: 29 April 2021

(c) The Author(s) 2021

\begin{abstract}
This paper aims to investigate the feasibility of the incorporation of nanosilica (NS) in ultra-lightweight foamed concrete (ULFC), with an oven-dry density of $350 \mathrm{~kg} / \mathrm{m}^{3}$, in regard to its fresh and hardened characteristics. The performance of various dosages of NS, up to $10 \mathrm{wt} .-\%$, were examined. In addition, fly ash and silica fume were used as cement replacing materials, to compare their influence on the properties of foamed concrete. Mechanical and physical properties, drying shrinkage and the sorption of concrete were measured. Scanning electron microscopy (SEM) and X-ray microcomputed tomography $(\mu-\mathrm{CT})$ and a probabilistic approach were implemented to evaluate the microstructural changes associated with the incorporation of different additives, such as wall thickness and pore anisotropy of produced ULFCs. The experimental results confirmed that the use of NS in optimal dosage is an effective way to improve the stability of foam bubbles in the fresh state. Incorporation of NS decrease the pore anisotropy and allows to produce a foamed concrete with increased wall thickness. As a result more robust and homogenous microstructure is produced which translate to improved mechanical and transport related properties. It was found that replacement of cement with $5 \mathrm{wt} . \%$ and $10 \mathrm{wt} .-\% \mathrm{NS}$ increase the compressive strength of ULFC by $20 \%$ and $25 \%$, respectively, when compared to control concrete. The drying shrinkage of the NSincorporated mixes was higher than in the control mix at early ages, while decreasing at $28 \mathrm{~d}$. In overall, it was found that NS is more effective than other conventional fine materials in improving the stability of fresh mixture as well as enhancing the strength of foamed concrete and reducing its porosity and sorption.
\end{abstract}

Keywords Ultra-lightweight foamed concrete $\cdot$ Cement-based composite $\cdot$ Nanosilica $\cdot$ Microstructure $\cdot$ Compressive strength $\cdot$ Shrinkage

\section{Introduction}

Pawel Sikora

pawel.sikora@zut.edu.pl

$\bowtie$ Sang-Yeop Chung

sychung@sejong.ac.kr

Mohamed Abd Elrahman

mohamedattia@mans.edu.eg

Dietmar Stephan

stephan@tu-berlin.de

1 Building Materials and Construction Chemistry, Technische Universität Berlin, Berlin, Gustav-Meyer-Allee 25,

13355 Berlin, Germany

2 Structural Engineering Department, Mansoura University, Elgomhouria St., Mansoura 35516, Egypt

3 Department of Civil and Environmental Engineering, Sejong University, 209 Neungdong-ro, Gwangjin-gu, Seoul 05006, Republic of Korea
Many studies have recently focused on the properties of different types of lightweight concrete, due to its various advantages, including excellent sound and thermal insulation properties as well as its low density [1]. Foamed concrete (FC) is a type of low density, cement-based lightweight concrete, consisting of cement paste with randomly distributed air bubbles introduced by foaming agents [2]. Foam bubbles can be produced in cement paste either by mixing a foaming agent with the cement paste or through a pre-forming process [3]. Foamed concrete is widely used due to its superior properties, such as self-levelling ability, high insulation properties, filling ability, fire-resistant characteristics and low cost compared to other types of lightweight concrete. FC can also withstand the freezing conditions, and its performance can be controlled by adjusting the pore structure with the use of supplementary cementitious materials 
(SCMs) [4]. However, it should be taken into account that the production of FC is highly sensitive to alteration in the mixture design and production procedure when compared to the production of lightweight aggregate concrete (LWAC) with the same density [5]. Kuzielova et al. [6] reported that the performance of FC can be controlled and improved by special treatments for foam by using ultrasound and microwave. In addition, Falliano et al. [7] showed that even a curing condition (in air or in water) plays a spectacular role on the resulting mechanical properties and fracture energy of FC. The potential usage of foamed concrete for structural and nonstructural applications and its mixture design and production procedures were also comprehensively summarized and reviewed [8].

In general, foamed concrete is produced with a density in the range of $500-1600 \mathrm{~kg} / \mathrm{m}^{3}$. However, at a density $<500 \mathrm{~kg} / \mathrm{m}^{3}$, it tends to be unstable due to the high foam content and low cement paste content, which significantly limits its applications [3]. At such low densities, it is generally designated as ultra-lightweight foamed concrete (ULFC) and requires more attention than conventional concrete, when selecting its constituents, as well as in the mixing process, to improve its stability, strength and physical characteristics.

It is now available to produce and characterize foamed concrete with ultra-low plastic densities $\left(<500 \mathrm{~kg} / \mathrm{m}^{3}\right)$, in particular, as a result of ongoing development in the field of concrete technology, which has included the introduction of new evaluation techniques including X-ray micro-computed tomography (micro-CT) [9], X-ray diffraction (XRD) and scanning electron microscopy (SEM) [10]; this, in turn, enables to understand the role of SCMs and various designing processes towards optimizing the mixture designs. However, numerous research and engineering experiences have shown that ultra-lightweight foamed concrete can be unstable, particularly as its density decreases [8]. Kuzielova et al. [11] reported that even a small variation in density could affect significantly the compressive strength of specimens in the case of ULFCs with a bulk density below $200 \mathrm{~kg} / \mathrm{m}^{3}$. Chung et al. [12] also confirmed that with decreasing the density of ULFC the amount of pores of larger diameter were noticeably increasing. In addition, at low densities, ULFC suffers from low strength and is highly susceptible to cracking [8]. As a result, the applications and design of FC are somewhat limited and requires very precise producing process to achieve a material with the desired low density.

To date, many comprehensive studies on the effects of various chemical admixtures, additives and fibers on the properties of lightweight concretes, have been performed. Chung et al. [13] used micro-CT to evaluate the effect of pore size, distribution and shape on physical and mechanical properties of foamed concrete and they found that with increasing the density of concrete the solid content increase which keep the spherical shape of the pores and make them more isotropic. Abd Elrahman et al. [14] compared three different approaches towards incorporating air voids in cement pastes by adding aluminum powder, air-entraining agent, and hollow microspheres and figured out the significant differences between the compressive strength of cement-based composites according to air-entraining admixtures. Zhihua et al. [15] reported that cracking phenomenon of FC can be partially mitigated by the replacement of cement with 15-20 wt.-\% of ultrafine blast furnace slag powder as well as the introduction of polypropylene fibers. Similarly Falliano et al. [16] suggested an approach to overcome the low bending strength of ULFC with different densities $(400,600$, $800 \mathrm{~kg} / \mathrm{m}^{3}$ ) by using polymer fibers and their results showed that the addition of fibers increased the flexural capacity of the beams, especially for the low-density specimens. A comprehensive evaluation of the effects of type of foaming agent was also performed highlighting the importance on choosing the proper foaming agent as well as curing conditions towards optimizing the production process of ULFC [17]. Huang et al. [18] evaluated the methods towards hindering the collapse and air-voids escape phenomena during foam concrete production by adding thickening agent and foam stabilizing emulsion. Jones et al. [19] presented the possibility of the production of low embodied carbon dioxide FC containing a high volume of fly ash.

Above mentioned studies have shown that the inclusion of supplementary cementitious materials (SCMs) has a significant effect on controlling the mechanical, transport and durability performance of ultra-lightweight foamed concretes; these effects can mainly be attributed to a refinement of the pore and void structures, as well as to the improvement of foam bubble stability when a proper SCM is included in the mixture. Jones et al. found that [19] replacement of cement with a high volume of fly ash (up to 70\%) reduces the average bubble size of the FC and increase the thickness of the bubble walls. Similar findings were found by Hilal et al. [20] in relation to silica fume used as a SCM. Another approach to improve the stability of foam was proposed by Xin et al. [21], where silica fume was added to the foam prior mixing it with cement. As a result of the chemical interaction of foam and silica fume, the stability of foam was improved. However, despite its beneficial effects on the properties of ULFCs, the incorporation of SCMs can also cause undesirable drawbacks, such as increased shrinkage and late strength development. Jones and McCarthy [22] reported that due to high drying shrinkage strain and relatively low tensile strength and stiffness performance straight substitution for normal- weight concrete is not possible. Roslan et al. [23] found that ULFC containing $15 \mathrm{wt} .-\%$ and $30 \mathrm{wt} .-\%$ of cement replacement with fly ash exhibited half and oneforth of compressive strength, respectively, after 7 days of curing when compared to pristine concrete. However, after 
28 days of curing compressive strength of FC containing fly ash is usually found to be comparable or higher than that of pristine FC [24]. Raj et al. [25] have reported that the drying shrinkage of foamed concrete is 10 times higher than that of conventional concrete. The addition of typical SCMs can be successfully applied to reduce shrinkage to a certain extent, due to the low amount of hydration heat produced [26]. The drying shrinkage of foamed concrete can also be reduced significantly by decreasing the pores connectivity [27]. Incorporation of lightweight aggregates can reduce the drying shrinkage without a significant increase in the density of foamed concrete [28]. Abd Elrahman et al. [29] reported that fly ash addition can reduce the drying shrinkage of ultralightweight foamed concrete with dry density lower than $500 \mathrm{~g} / \mathrm{m}^{3}$ by about $30 \%$. It was also reported that silica fume improves early strength but can have a negative effect on drying shrinkage [25]. Therefore, in selecting SCMs, careful consideration must be given to the target property that is to be improved [8].

In recent years, nanomaterials (NMs) have attracted spectacular attention as admixtures for improving the performance of cement-based composites. Due to their ultrafine particle size, as well as their high chemical reactivity, they act as fillers with physical and chemical influence in cementitious systems, thus refining microstructure and accelerating the cement hydration process. There have been some notable contributions in the field of the modification of lightweight aggregate concretes (LWACs) with NMs [30], but evaluations of the effects of NMs on the properties of foamed concretes are still limited. Studies on the effects of carbon nanotubes (CNTs) on the properties of ULFCs have shown that the use of CNTs contributes significantly to early strength development and $28 \mathrm{~d}$ strength. It was also reported that CNTs can affect the improvement in the uniformity of air void structures [31]. Luo et al. [32] reported a $27 \%$ improvement in the compressive strength of ULFC, with a density of $300 \mathrm{~kg} / \mathrm{m}^{3}$, through the addition of a low dosage of CNTs, together with a reduction in the average pore diameter. Zhang and Liu [33] presented that better dispersion of CNTs within the ULFC can be facilitated by the introduction of low dosages of nano- $\mathrm{Ce}\left(\mathrm{SO}_{4}\right)_{2}$, thus specimens exhibit better mechanical performance. Li et al. [34] have analyzed the effects of nano-montmorillonite on foamed concrete containing a high volume of fly ash, reporting an improvement in the compressive strength and microstructure of FC. Other researchers have used nanomaterials to stabilize the foam before mixing it with cement slurry $[2,35]$. The use of nanomaterials improves foam stability, leads to less or no collapsing of foam bubbles, refines pores and improves compressive strength at early ages. Moreover, the incorporation of nanoparticles has been found to significantly improve compressive strength, due to a narrow pore size distribution, compared to normal foamed concrete [2].
Among the NMs, silica nanoparticles $\left(\mathrm{SiO}_{2}\right)$ are the material which is considered to be the most promising material for application in cementitious composites with few commercially available products on the market. While knowledge regarding the effects of nanosilica (NS) on the properties of normal-weight cementitious composites is widely established, little research has so far been conducted to evaluate the mechanisms of the effects of nanosilica (NS) on the properties of ULFCs. Therefore, this study aims at shedding light on the design and performance of ultralightweight foamed concretes (with a density $350 \mathrm{~kg} / \mathrm{m}^{3}$ ) modified with nanosilica. To realize this goal comprehensive evaluation of the compressive strength, drying shrinkage, thermal conductivity and the sorption of foamed concrete were performed. In addition, X-ray microcomputed tomography $(\mu-\mathrm{CT})$ was adapted to characterize the wall-thickness and pore structure incorporating a probabilistic method. The results obtained were compared with selected mixtures utilizing conventional SCMs, such as silica fume and fly ash. As an outcome reported experimental results were linked with the microstructural characteristics obtained by $\mu-C T$ and scanning electron microscopy (SEM) studies.

\section{Materials and methods}

\subsection{Materials}

Ordinary Portland cement, CEM I 52.5 R complying with EN 197-1, was used in this research (HeidelbergCement AG, Germany). Three different fine materials were selected and used as SCMs: class F fly ash (FA) (Baumineral, Germany), silica fume (SF) (Sika, Germany) and nanosilica (Levasil CB8, Nouryon, Sweden) in slurry form (NS). The same silica nanoparticles were used in or previous studies $[30,36]$ and have been comprehensively characterized in the work [36]. Transmission electron microscope (TEM) micrographs (Fig. 1a-c) shows spherically shaped silica nanoparticles, with a energy dispersive X-ray (EDX) spectrum (Fig. 1e) and X-ray diffraction (XRD) patterns (Fig. 1f) confirming its high purity and amorphicity. Table 1 summarise basic properties of NS suspension used in this study.

Table 2 shows the chemical and physical properties of the cement, fly ash and silica fume, while Fig. 2 depicts the particle size distribution of these materials. Since nanosilica was used in slurry form, the amount of the liquid phase was deducted from the effective water (w/b). In most foamed concrete mixtures, according to the authors' knowledge, fine aggregate (sand) is used to reduce volumetric changes and concrete shrinkage. However, this addition can cause a significant increase in the density of the foamed concrete. Therefore, in this research, lightweight fine sand (expanded glass, Liaver), was used in a $0.1-0.3 \mathrm{~mm}$ fraction, with a 

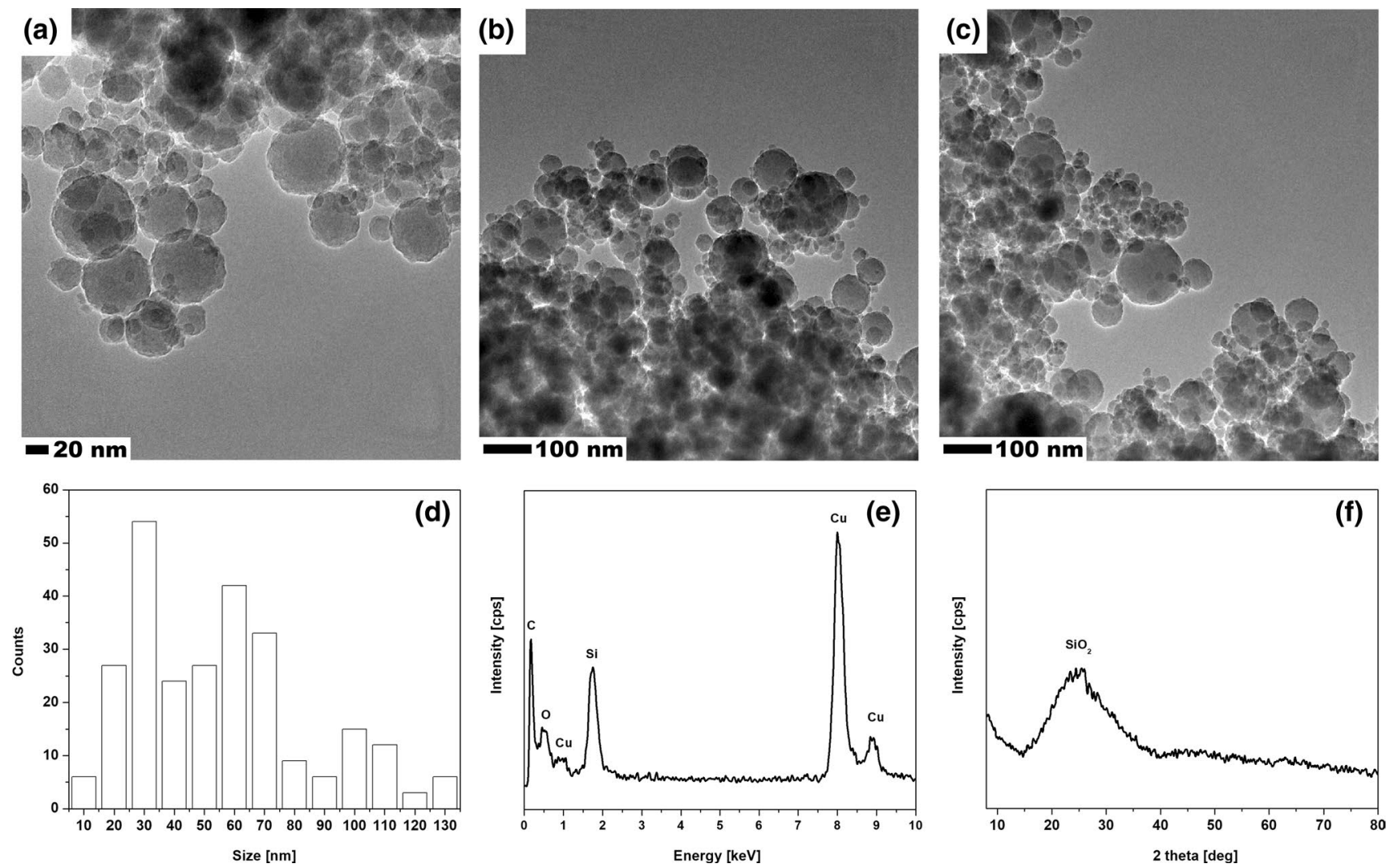

Fig. 1 TEM images (a-b), particle size distribution (c), EDX (e) and XRD (f) analysis of nanosilica. The carbon and copper signals present in the spectrum come from the holey carbon TEM grid. Reproduced from [36]

Table 1 Properties of silica nanoparticles suspension

\begin{tabular}{lllll}
\hline Particle size* & Solid content & Density & Viscosity & $\mathrm{pH}$ \\
\hline $10-140 \mathrm{~nm}$ & $50 \mathrm{wt} .-\%$ & $1.4 \mathrm{~g} / \mathrm{cm}^{3}$ & $8 \mathrm{cP}$ & 9.5 \\
\hline
\end{tabular}

*Based on TEM analysis

density of $0.8 \mathrm{~g} / \mathrm{cm}^{3}$, to facilitate the production of concrete with an ultra-low density. The water absorption of the lightweight aggregates used was determined to be $12 \mathrm{wt} .-\%$, with an additional amount of water, equal to the absorption of fine lightweight sand, included in the effective water. A foaming agent, with a density of $1.05 \mathrm{~g} / \mathrm{cm}^{3}$ (Lightcrete 400) and produced by Sika Germany, was used to produce the foam. In addition, superplasticizer compatible with the used foaming agent has been implemented to achieve the required consistency. To improve the homogeneity and stability of the foamed concrete mixture, a viscosity-enhancing admixture (Sika Stabilizer ST3) was adopted, to prevent segregation in the fresh mixture.

\subsection{Mix composition}

Seven foamed concrete mixtures were designed and prepared, to achieve a dry target density in the range of $350 \pm 50 \mathrm{~kg} / \mathrm{m}^{3}$. Paste/foam ratio is the most important parameter controlling the density and stability of foamed concrete. In this study, it was fixed at 1:3 by volume, for all the mixes, to achieve the target density. The water/binder ratio was fixed at 0.40 for all the mixes. Various empirical models have been proposed to predict the dry density of foamed concrete [8]. In this study, theoretical dry density
Table 2 Chemical and physical composition of cement, SF and FA

\begin{tabular}{lrrrlllllll}
\hline Material & $\mathrm{CaO}$ & $\mathrm{SiO}_{2}$ & $\mathrm{Al}_{2} \mathrm{O}_{3}$ & $\mathrm{Fe}_{2} \mathrm{O}_{3}$ & $\mathrm{MgO}$ & $\mathrm{Na}_{2} \mathrm{O}$ & $\mathrm{K}_{2} \mathrm{O}$ & $\mathrm{SO}_{3}$ & Density $\left(\mathrm{g} / \mathrm{cm}^{3}\right)$ & $\begin{array}{l}\text { Surface area } \\
\left(\mathrm{cm}^{2} / \mathrm{g}\right)\end{array}$ \\
\hline CEM I 52.5R & 66.2 & 20.6 & 3.3 & 4.9 & 1.3 & 0.1 & 0.43 & 2.8 & 3.15 & 3860 \\
Fly ash & 4.8 & 47.9 & 21.0 & 4.6 & 1.4 & 0.7 & 1.1 & 0.8 & 2.27 & 2930 \\
Silica fume & 0.2 & 98.4 & 0.2 & 0.01 & 0.10 & 0.15 & 0.2 & 0.1 & 2.0 & 200,000 \\
\hline
\end{tabular}


Fig. 2 Particle size distribution of the fine materials used

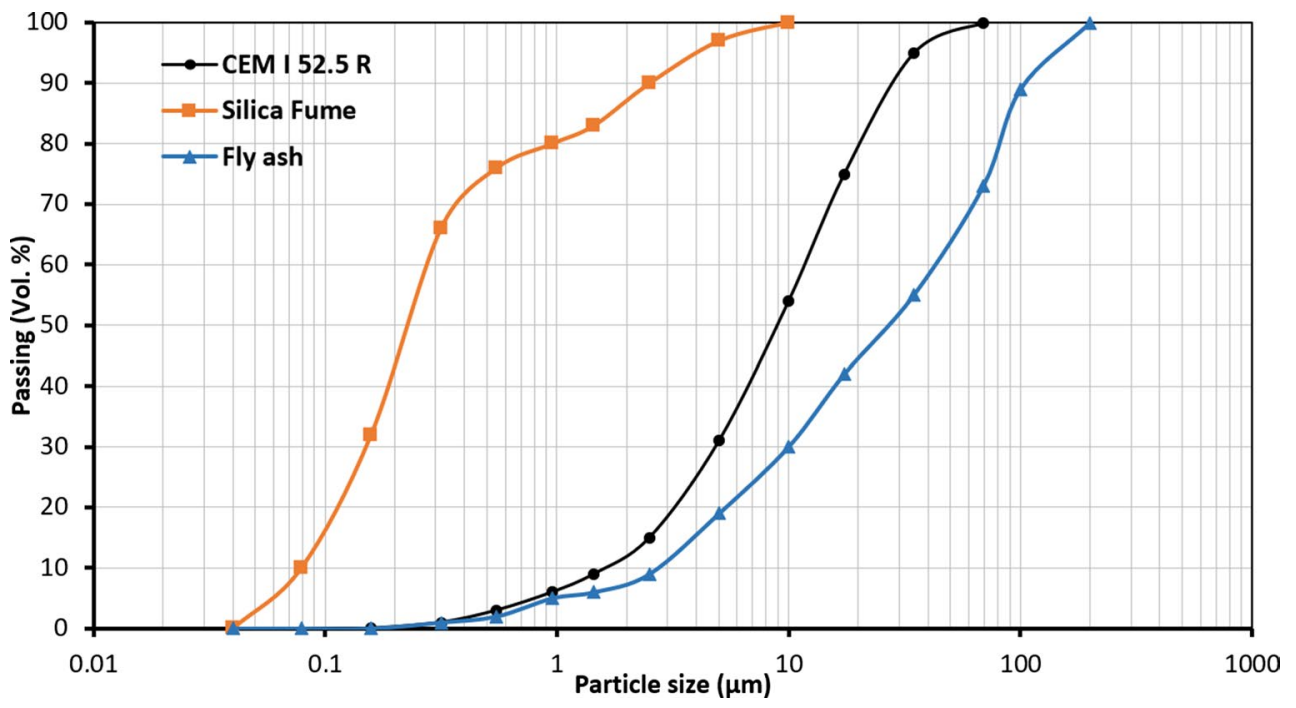

was calculated based on the following formula, where it was assumed that $20 \mathrm{wt} .-\%$ of the cement stone was chemically bound water, which could not be evaporated by standard drying below a temperature of $105 \pm 5^{\circ} \mathrm{C}$ (Eq. 1) [8]:

Oven - dry density $\left(\mathrm{kg} / \mathrm{m}^{3}\right)=1.2 C+A$

where $C$ is the mass of the cementitious materials added $(\mathrm{kg} /$ $\left.\mathrm{m}^{3}\right)$ and $A$ is the mass of the aggregates $\left(\mathrm{kg} / \mathrm{m}^{3}\right)$. According to this formula, $60 \mathrm{~kg} / \mathrm{m}^{3}$ of fine lightweight aggregate required a cementitious material content of $240 \mathrm{~kg} / \mathrm{m}^{3}$, for all mixtures.

Four dosages were used to study the influence of nanosilica on the performance of foamed concrete: 1.25, 2.5, 5, and 10 wt.- $\%$ of cement. For comparison, a control mix containing pure cement, mix containing fly ash with 25 wt.- $\%$ cement replacement and mix containing silica fume with $10 \mathrm{wt} .-\%$ cement replacement were prepared and also tested. Table 3 presents the compositions of the different concrete mixtures. Both the amount of mixing water and superplasticizer remained constant in all cases, while the stabiliser content was adapted to prevent segregation and bleeding of the foamed concrete. Foamed concrete compaction is not desirable due to the high probability of segregation, destruction and merging of foam bubbles and because of the resultant formation of big voids. The concrete mixture was therefore designed to achieve a consistency class of F4/F5 (according to EN 206-1), to produce a workable homogeneous mix with a high filling ability, without the need for vibrations.

\subsection{Preparation of foamed concrete}

The pre-formed foam in this investigation was produced and then mixed with cement slurry. An SG S9 foam generator (Sika Germany) was adapted and used to produce the foam, at a capacity of $9 \mathrm{~L}$ per minute and with a pressure of 0.4 bars. Tap water, with a pressure of about 3 bars and compressed air with a pressure of 2 bars, were applied to the generator, with the foaming agent dosage set at 2 wt.- $\%$ of the water. The foam produced had to be stable and, as recommended by the provider, was to be continuously produced without pulses. For this purpose, the compressed air pressure was adjusted until the foam was produced uniformly and steadily. The foam density was measured as $35-40 \mathrm{~kg} /$
Table 3 Foamed concrete mixture compositions $\left(\mathrm{kg} / \mathrm{m}^{3}\right)$

\begin{tabular}{llllllllll}
\hline Mix & Cement & FA & SF & $\begin{array}{l}\text { NS } \\
\text { (slurry)* }\end{array}$ & $\begin{array}{l}\text { Fine Liaver } \\
\text { aggregate }\end{array}$ & Water & SP & ST & $\begin{array}{l}\text { Paste: Foam } \\
\text { (volume) }\end{array}$ \\
\hline C & 240 & - & - & - & 60 & 96 & 1.6 & 1.0 & $1: 3$ \\
FA25 & 180 & 60 & - & - & 60 & 96 & 1.6 & 1.2 & $1: 3$ \\
NS1.25 & 237 & - & - & 6 & 60 & 93 & 1.6 & 1.0 & $1: 3$ \\
NS2.5 & 234 & - & - & 12 & 60 & 90 & 1.6 & 0.8 & $1: 3$ \\
NS5 & 228 & - & - & 24 & 60 & 84 & 1.6 & 0.5 & $1: 3$ \\
NS10 & 216 & - & - & 48 & 60 & 72 & 1.6 & - & $1: 3$ \\
SF10 & 216 & - & 24 & - & 60 & 96 & 1.6 & 0.8 & $1: 3$ \\
\hline
\end{tabular}

*50 wt.- $\%$ of solid content. The liquid phase was considered to be a part of the mixing water 
$\mathrm{m}^{3}$. To avoid the occurrence of clumping and agglomeration, caused by mixing fine materials with water, an Eirich mixer with a high shear intensity $(1000 \mathrm{rpm})$ was applied to produce the cement slurry. The fine materials were firstly dry-mixed for $30 \mathrm{~s}$, after which water, superplasticizer and stabiliser were added and mixed for 2 min. The mixer was then stopped for one minute, prior to continuing mixing again for another minute. The foam was produced concurrently and the required volume was measured, to achieve a 1:3 ratio of paste to foam. Finally, a $50 \mathrm{~L}$ Zyklos concrete mixer, with a rotation speed of up to $80 \mathrm{rpm}$, was used to mix both components. The foam was first added to the bottom of the mixer, after which the cement slurry was gradually added. The mixing process continued until a homogeneous mixture was achieved (5-7 min). Afterwards, concrete specimens were cast by pouring the concrete directly into moulds, without vibration.

\subsection{Experimental tests}

Fresh property tests, including the flow table test and fresh density measurements, were performed according to EN 12350-5 and 12350-6, respectively. The flow test was performed without dropping or raising (jolting), as this might have an effect on the stability of the foam bubbles. A compressive strength test was carried out at $28 \mathrm{~d}$, according to EN 12390-3, using $100 \times 100 \times 100 \mathrm{~mm}^{3}$ cubes. The drying shrinkage of the foamed concrete was measured, as specified in DIN 52450, using the Graf-Kaufmann method, in which prisms with sample sizes of $40 \times 40 \times 160 \mathrm{~mm}^{3}$ are tested at 3, 7 and $28 \mathrm{~d}$ of curing. The Hot Disk device, according to ISO 22007-2, was used for thermal conductivity measurements. Cubical samples with an edge length of $100 \mathrm{~mm}$ were used for determining oven-dry density and thermal conductivity. For the Hot Disk measurement, a sensor was positioned between two samples, with the sensor concurrently used as both a temperature monitor and current supplier [37]. To evaluate the water uptake of the foamed concrete, sorption (absorption) tests, in accordance with EN ISO 15148 , were carried out on $40 \times 40 \times 160 \mathrm{~mm}^{3}$ sample prisms. In all cases, at least three specimens were tested, with the mean value taken into consideration.

\subsection{Microstructural studies}

Material characteristics, such as pore and solid structures, strongly affect the physical and mechanical properties of foamed concrete [10]. They must therefore be examined in a detailed manner, using the proper method. In this study, $\mathrm{X}$-ray micro-computed tomography (micro-CT), a nondestructive and non-invasive method, was utilized. The method has been widely used by various researchers to examine the microstructures of cement-based composites without specimen damage [38-40] and as such, the pore and solid characteristics of foamed concrete with nanosilica, can also be examined using this approach.

The original micro-CT image was obtained by using a self-made CT device, consisting of a Hamamatsu microfocus X-ray source. Detailed configuration of the device used can be found in [41]. Figure 3 shows the micro-CT imaging procedure used to generate a $3 \mathrm{D}$ volume of the microstructure. The original micro-CT image shows an initially reconstructed 8-bit image of the target sample. For more effective investigation and in consideration of computational costs, a proper region that can represent the whole specimen was selected from the original image and denoted as a region of interest (ROI). The selected ROI was composed of $400 \times 400$ pixels, with a pixel size of $31.0 \mu \mathrm{m}$. The 8 -bit image was expressed in terms of 256 values, ranging from 0 (black) to 255 (white), with a threshold value needing to be selected to segment a target component from the original image. The modified Otsu [42] and manual selection methods $[5,43]$ were used for thresholding, with it being possible to obtain the binarised image using the selected threshold value and the image toolbox in MATLAB (R2020a). In the binary image, the white represents the background (solid) part, while the black represents pores within the specimen. A modified watershed algorithm [13] was then adopted for the binary image, to describe each pore more clearly. 3D volume images of the pore structures were generated by stacking the series of segmented cross-sectional images, as shown in Fig. 4. Using the 3D binary volume in Fig. 4, the pore size distribution and the average wall thickness of the specimens produced were investigated. The NS1.25 and NS2.5 microstructures were not taken into consideration in the micro-CT investigation, because they showed inferior mechanical and thermal properties, compared to the other specimens.

To support the micro-CT evaluations, the scanning electron microscopy (SEM) technique was applied. After $28 \mathrm{~d}$ of curing, specimens were cut into small pieces, dried in a freeze-dryer and evaluated with the use of a low-vacuum scanning electron microscope (SEM, Zeiss GeminiSEM500 NanoVP).

\section{Results and discussion}

\subsection{Fresh properties}

The fresh properties of the foamed concrete were evaluated by measuring flow diameter and fresh density. The targeted consistency class of the foamed concrete was F4/F5 (in accordance with EN 206-1), which ensures high filling and self-levelling ability (Fig. 5). With the help of superplasticizer, all the concrete mixtures satisfied the required consistency class. In general, incorporation of air/foam 


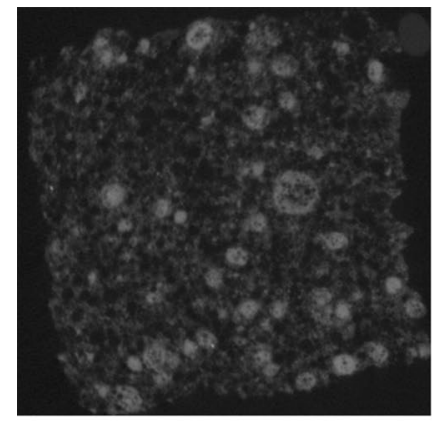

Original micro-CT

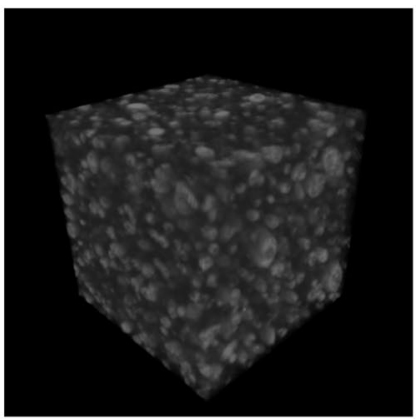

3D micro-CT image

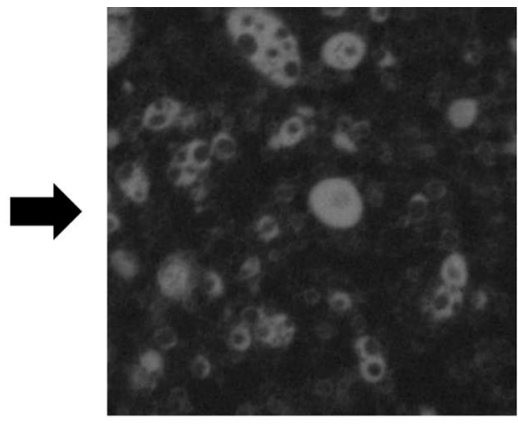

Region of interest (ROI)

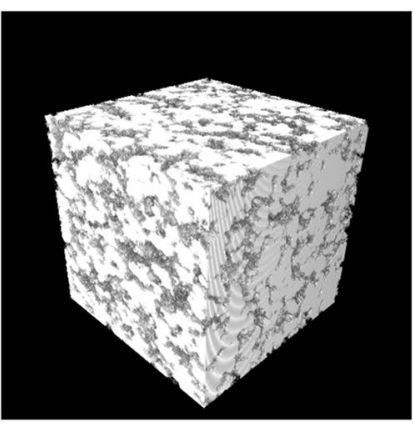

3D volume of solid part

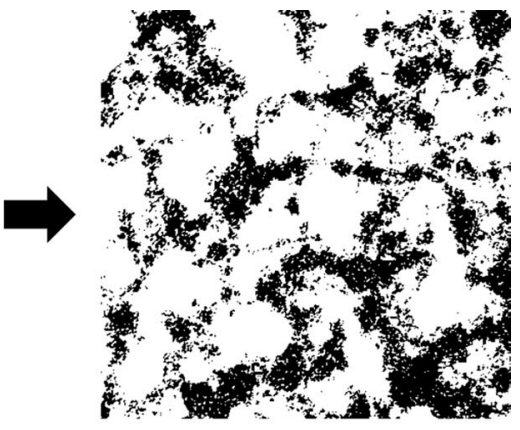

Binarized image
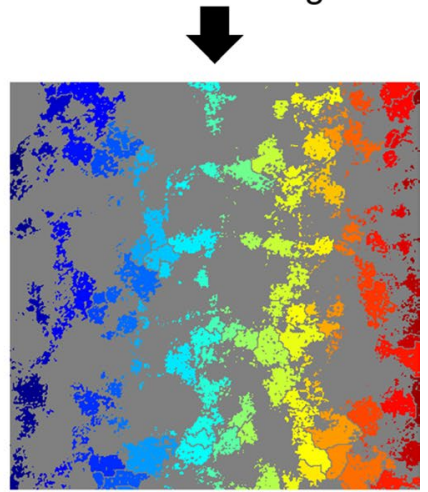

Watershed pore image

Fig. 3 Micro-CT imaging process for generating 3D volume of the microstructures (Note: in the binarised image, the white is the background solid part, while the black presents pores, which are presented as a colored region in the watershed pore image.)

bubbles can improve the workability of fresh concrete due to its ball bearing (sphericity). However, for ultra-lightweight concrete with very low density, this influence is vanished due to the reduced mass of concrete which motivate the particles to move. Increasing the water/binder ratio can improve workability, but at the same time, this can lead the concrete to suffer from segregation as a result of excessive water addition, thus negatively affecting its performance. Therefore, it is desirable to add superplasticizer and to use the minimum water content. However, it was observed that mixtures containing NS exhibited better cohesion between the cement paste and foam, thereby necessitating a lower amount of stabilizer, as can be seen in Table 3. Both the control mix with cement alone (C) and mix FA25, suffered bleeding and high segregation due to the difference in densities between the cement paste and the foam. Consequently, a high amount of stabilizer (viscosity-enhancing admixture) was added, to improve the homogeneity and stability of the mixes. The amount of stabilizer required decreased with increasing NS dosage. Very fine materials, such as nanosilica and silica fume, improve the cohesion and adhesion of concrete constituents. As a result, the doses of stabilizer required gradually decreased with increasing NS content, which decreased the contact area between foam voids and formed a compacted layer which prevented bubbles from merging. The role of nanoparticles as foam stabilizers has been reported on by Sun et al. [27]. Moreover, the seeding effect of NS leads to the earlier formation of the $\mathrm{C}-\mathrm{S}-\mathrm{H}$ phase [44], resulting in a substantial effect on thixotropic properties and the early strength development of concrete [45]. Figure 6 presents the results of the fresh density tests of the foamed concrete. All the mixes showed a fresh density in the range of $430-525 \mathrm{~kg} / \mathrm{m}^{3}$.

\subsection{Properties of hardened concrete}

\subsubsection{Oven-dry density and thermal properties}

The oven-dry density of the foamed concrete was measured after drying, at $105 \pm 5{ }^{\circ} \mathrm{C}$, till constant mass, in accordance with EN 12390-7. In the case of normalweight concrete, complete drying takes about $72 \mathrm{~h}$, depending on the pore structure of the concrete. However, for lightweight concrete with high porosity and a broad range of pores within the cement matrix, as well as with fine aggregates, more than a week is needed for complete drying to constant mass. The results taken into consideration in this investigation were the means of three measured values for each mix, with the samples dried until constant mass (difference $<0.2 \mathrm{wt}$.- \%). It is 


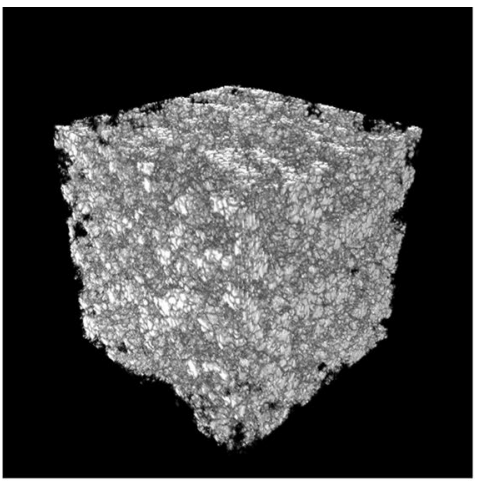

C

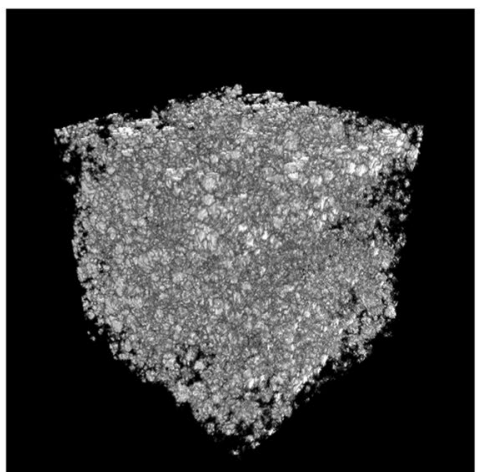

FA25

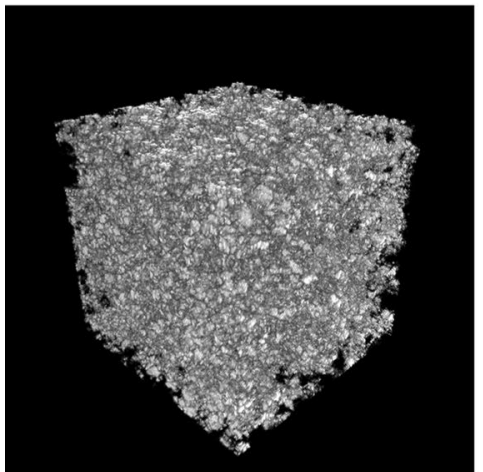

NS5

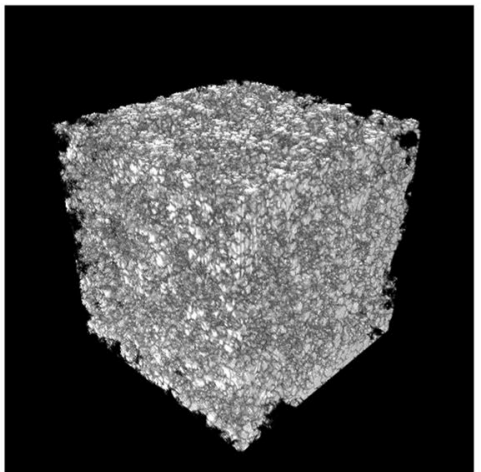

NS10

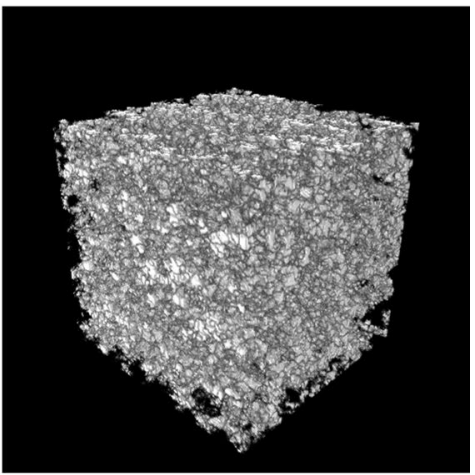

SF10

Fig. 4 Pore structures of the specimens used (Note: in each image, the white represents the pores within the specimens.)

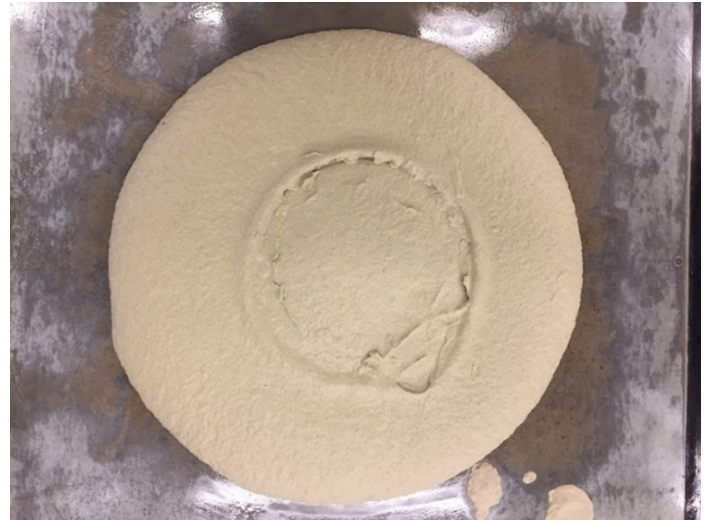

Fig. 5 Consistency of ultra-lightweight foamed concrete

obvious, from the experimental results (Fig. 7), that the addition of fly ash increased the density of the foamed concrete at the same foam volume, which is in agreement with the observations of Nambiar et al. [46]. Similarly, the density increased with NS content, up to a specific dosage. Above 5 wt.- $\%$ of NS addition, the density of the hardened foamed concrete decreased significantly. Most of the concrete mixes exhibited densities in the range

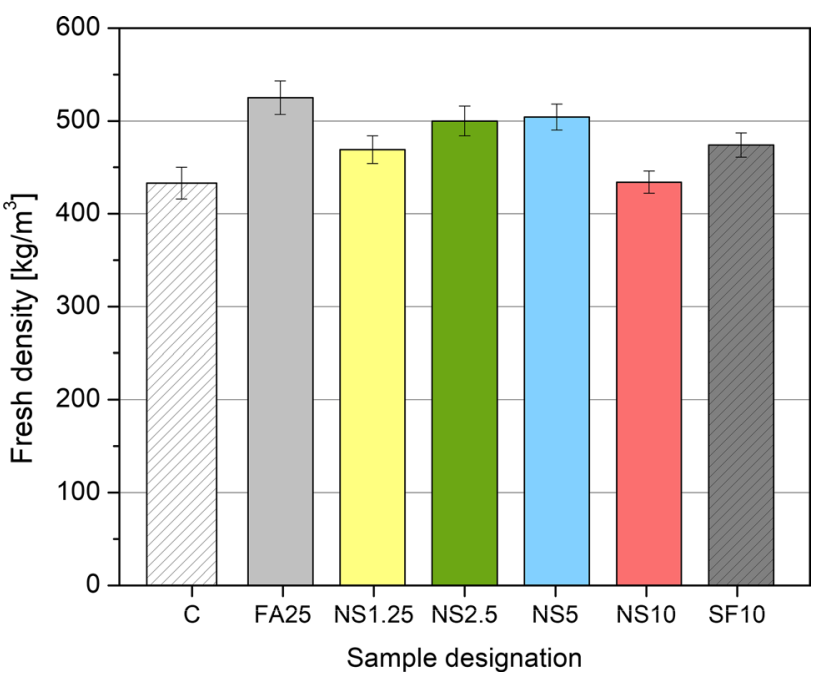

Fig. 6 Fresh concrete mixture densities

of $350 \pm 50 \mathrm{~kg} / \mathrm{m}^{3}$, which is an acceptable tolerance for lightweight concretes $[8,11]$. However, the FA25 mix exhibited a higher density of $419 \mathrm{~kg} / \mathrm{m}^{3}$. A similar effect has been reported by Amran et al. [8]. To achieve the target density, the foamed concrete specimens produced, 


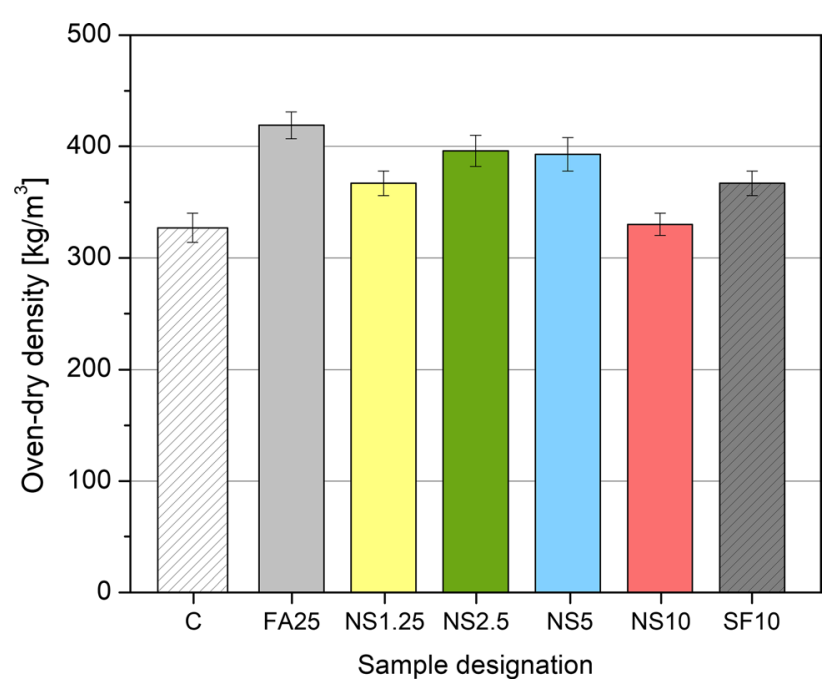

Fig. 7 Oven-dry density of foamed concrete mixes

contained a large volume of air bubbles, which increased the probability of bubbles merging, thus making the concrete very sensitive to input constituents. Due to its small particle size, the addition of fly ash tends to generate more regularly distributed air pores, by coating the bubbles with a uniform layer, which prevents them from merging [47]. Furthermore, due to the spherical shape of the fly ash particles, packing with cement grains also improved, such that the solid structure densified. All of these factors resulted in an increase in the dry density of the foamed concrete when fly ash was added. Similarly, the addition of silica fume increased the oven-dry density, compared to the control mix (C), by about $10 \%$.

In comparison to other types of concrete, foamed concrete has superior thermal insulation characteristics. The results in Fig. 8 show a clear trend in which thermal conductivity increased with dry density. The role of the fine materials on the thermal insulation was marginal and indirect since their addition was able to increase density, thereby increasing thermal conductivity. A similar observation has been reported by Ramamurthy et al. [28]. The range of the measured thermal conductivity of the mixes under examination was about $0.125-0.163 \mathrm{~W} / \mathrm{m} \cdot \mathrm{K}$, which is similar to that of other research in similar density classes. Jones et al. [19] have reported a thermal conductivity in the range of $0.10-0.19 \mathrm{~W} / \mathrm{m} \cdot \mathrm{K}$ for foamed concrete, with a dry density of $300-500 \mathrm{~kg} / \mathrm{m}^{3}$, while Huang et al. [18] recorded a thermal conductivity value of $0.08 \mathrm{~W} / \mathrm{m} \cdot \mathrm{K}$ for foamed concrete with a dry density of $300 \mathrm{~kg} / \mathrm{m}^{3}$. Mix FA25, with the highest dry density, exhibited high thermal conductivity due to the high solid content and corresponding high density, which served as a medium for heat transfer through the concrete.

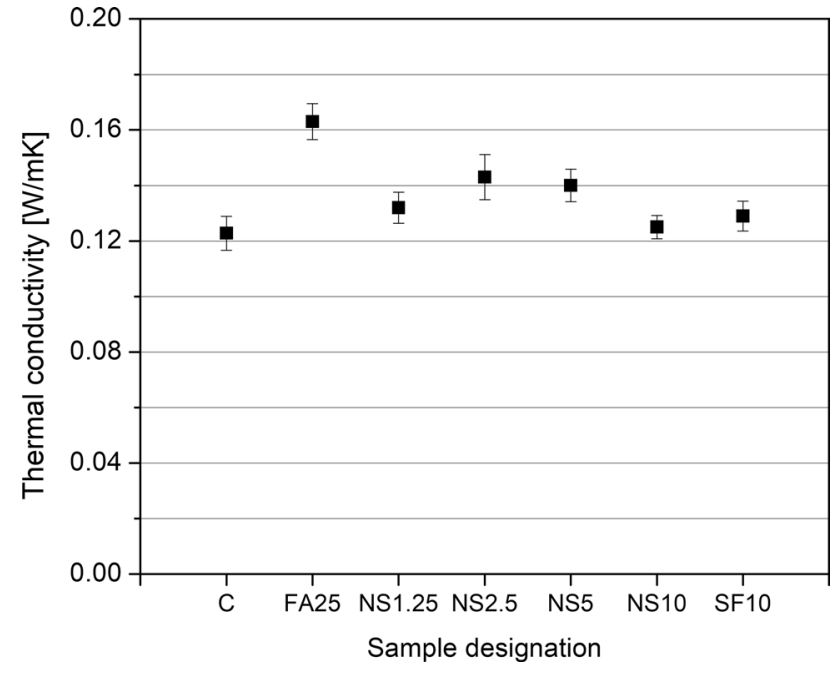

Fig. 8 Foamed concrete thermal conductivity

\subsubsection{Compressive strength of foamed concrete}

The results of $28 \mathrm{~d}$ compressive strength are presented in Fig. 9. Mix FA25 had the highest compressive strength value and the highest density. All of the concrete mixes exhibited compressive strengths ranging from 1.0 to $1.9 \mathrm{MPa}$, which is comparable to the values obtained by other researchers, with similar density. Jones et al. [19], have reported compressive strengths of 0.2-0.4 MPa for foamed concretes with densities in the range of $300-500 \mathrm{~kg} / \mathrm{m}^{3}$, while Huang et al. [18] have recorded compressive strengths of about $1 \mathrm{MPa}$ for foamed concrete, with a dry density of about $300 \mathrm{~kg} /$ $\mathrm{m}^{3}$. The mixing process applied in the current research had a significant role in improving foam bubble stability and

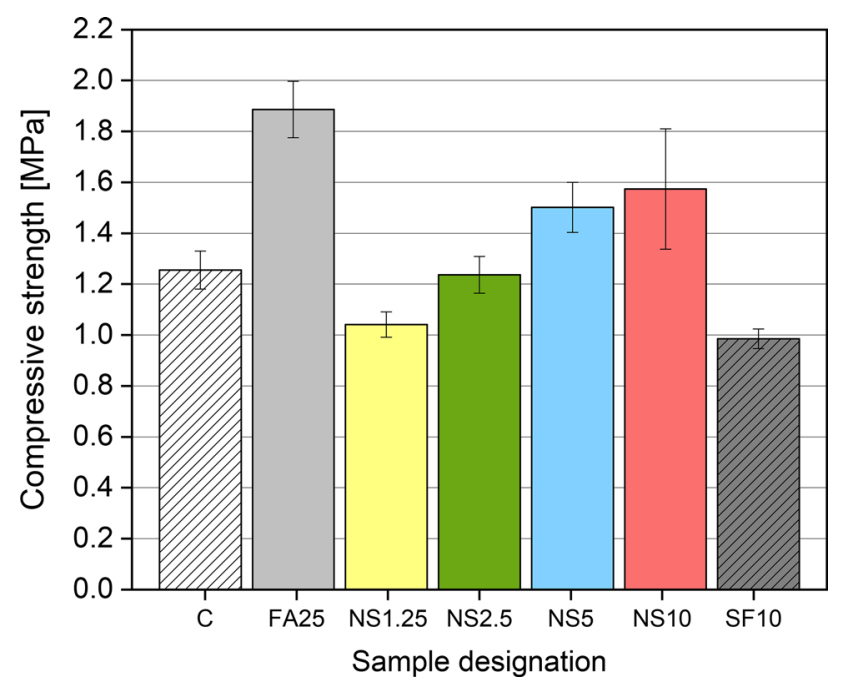

Fig. 9 Compressive strength results of foamed concretes, at the age of $28 \mathrm{~d}$ 
solid structures homogeneity as well as in preventing the agglomeration of fine particles, which led to improvements in the stability and strength of the resultant foamed concrete.

The inclusion of NS had a clear effect on the strength development of the foamed concrete, with compressive strength increasing with NS dosage. However, with a lower nanosilica content (NS1.25), the strength obtained was lower than that of the control mixture. With an increase in the dosage up to $5 \mathrm{wt} .-\%$ (NS5), the influence on compressive strength increased by about $20 \%$, compared to the control mix. The NS10 specimen exhibited a compressive strength of $1.57 \mathrm{MPa}$, which was higher than the control mix by about $25 \%$. The use of nanosilica can contribute to improve the stability of foam bubbles and can prevent the merging of large voids. The voids within the solid frame are small and have a narrow void size distribution, which can lead to an improvement in compressive strength, as has been confirmed by She et al. [2]. Also, due to its small particle size and very high surface area, nanosilica densifies the matrix and increase its strength, due to the pozzolanic reaction. However, the addition of silica fume does not contribute significantly to improving the strength of foamed concrete. As is shown in the following section, this can be attributed to the probability of micro-cracking in the foamed concrete, due to increased shrinkage when silica fume is used.

\subsubsection{Drying shrinkage of foamed concrete}

Due to the lack of coarse aggregates in foamed concrete, it suffers from much higher drying shrinkage compared to conventional concrete. Figure 10 shows the experimental results of drying shrinkage tests of the foamed concrete. It can be seen that drying shrinkage increased with age for all mixes. The drying shrinkage values obtained ranged between 0.21 and $0.44 \mathrm{~mm} / \mathrm{m}$. The results here are lower than those obtained by Jones et al. [19], at an almost identical density, because of the incorporation of fine lightweight aggregates. As has been reported by several researchers, the inclusion of lightweight aggregates can reduce cement paste drying shrinkage $[8,25]$. As can be seen from the results of mix FA25, which had the highest density and which exhibited the lowest drying shrinkage at all ages, drying shrinkage decreased with density. The SF10 mix showed the highest drying shrinkage, compared to the other mixes. The mixes containing nanosilica exhibited higher drying shrinkage at early ages. However, at $28 \mathrm{~d}$, the drying shrinkage of mixes with a nanosilica content of up to 5 wt.- $\%$, was lower than the control mix (C). The only exceptions were mixes NS10 and SF10, which exhibited higher drying shrinkages $(0.42$ and $0.44 \mathrm{~mm} / \mathrm{m}$, respectively) when compared to the control $\operatorname{mix}(0.33 \mathrm{~mm} / \mathrm{m})$. The influence of fine materials on the drying shrinkage of cement-based materials depends mainly on their content and characteristics. The mix with fly ash exhibited almost the lowest drying shrinkage at all ages, due to the reduced pozzolanic activity of fly ash, that reduced the hydration rate of the system. In contrast, very fine materials such as silica fume and nanosilica accelerate the hydration of cement and thereby increase volumetric changes in the microstructure, leading to higher drying shrinkage. This influence was more pronounced in mixes with high dosages of very fine materials, such as NS10 and SF10.

\subsubsection{Sorption of foamed concrete}

Sorption can be considered as an indicator of the durability characteristics of foamed concrete, since it is mainly controlled by capillary porosity [48]. The water uptake (coefficient of water absorption) of foamed concrete was

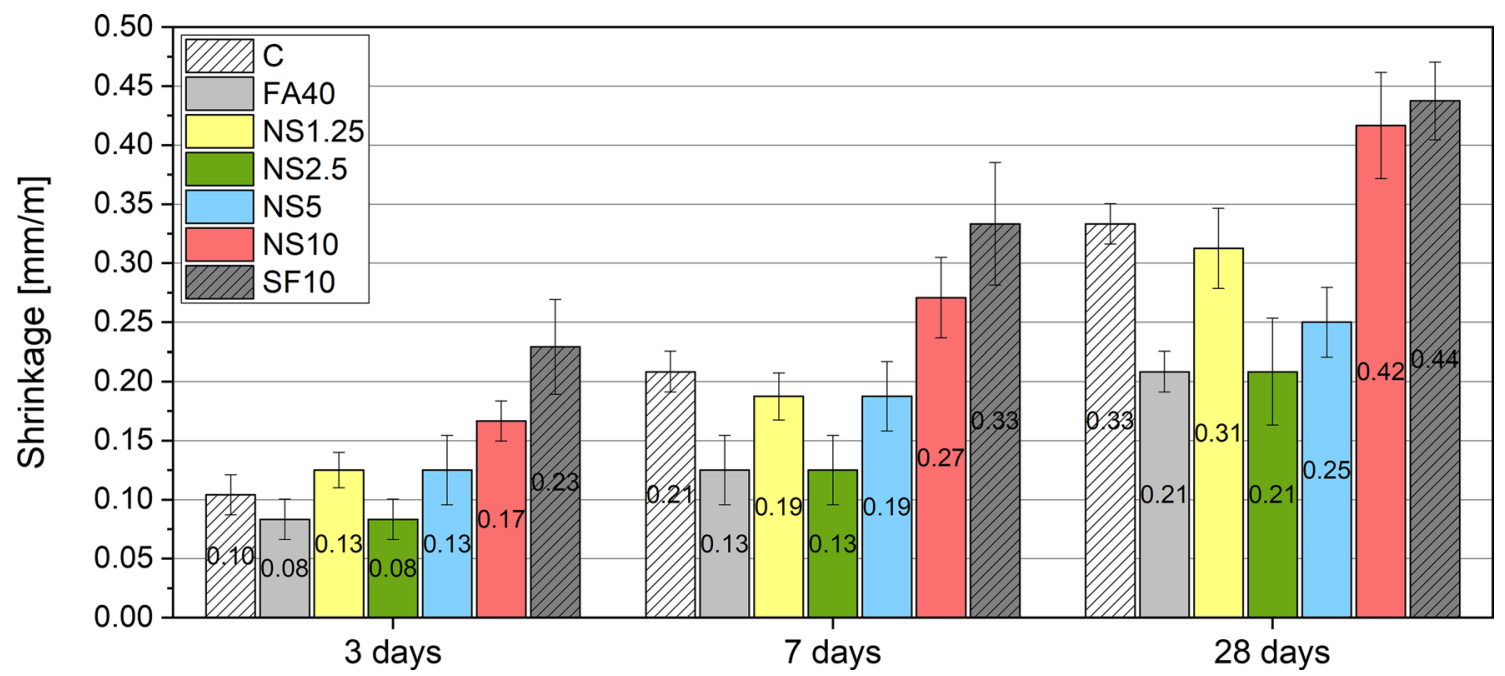

Fig. 10 Experimental results of drying shrinkage of foamed concretes at 3, 7, and $28 \mathrm{~d}$ 
measured in accordance with EN ISO 15148, using the partial immersion method. Capillary suction is the main force that absorbs the water inside concrete. The mass increase of a concrete sample, due to partial immersion in water, is measured at different time periods up to $24 \mathrm{~h}$. The water absorption coefficient can be calculated based on the values obtained. In this study, three samples were measured, with the mean value taken into consideration. Figure 11 presents the absorption coefficient of different foamed concrete mixes. The results reveal that the addition of very fine materials contributed significantly to a reduction in the absorption coefficient, because of the very small size of the particles of these materials, which compact the cement matrix and reduce capillary porosity. Moreover, due to nanosilica's high pozzolanity, it reacts with calcium hydroxide and produces denser $\mathrm{C}-\mathrm{S}-\mathrm{H}$, which refines the pores and reduces their connectivity. Similar results regarding the role of NS in reducing the water absorption of lightweight concrete can be found in [30]. The addition of fly ash increased the water absorption coefficient only in comparison to the reference mix with cement. The water absorption of concrete is governed only by capillary porosity and not by all types of pores. The addition of fly ash refines coarse pores and increases the number of small pores which might contribute to the movement of water through concrete under capillary force. Likewise, low dosages of nanosilica (1.25 and 2.5 wt.-\%) increase the sorption of foamed concrete. The water absorption started to decrease with the addition of 5 wt. $\%$ of nanosilica and decreased significantly with $10 \mathrm{wt} .-\%$. The pore structure of foamed concrete is complicated, with the size and connectivity of pores depending on many factors, especially in the case of such ultra-low density concrete.

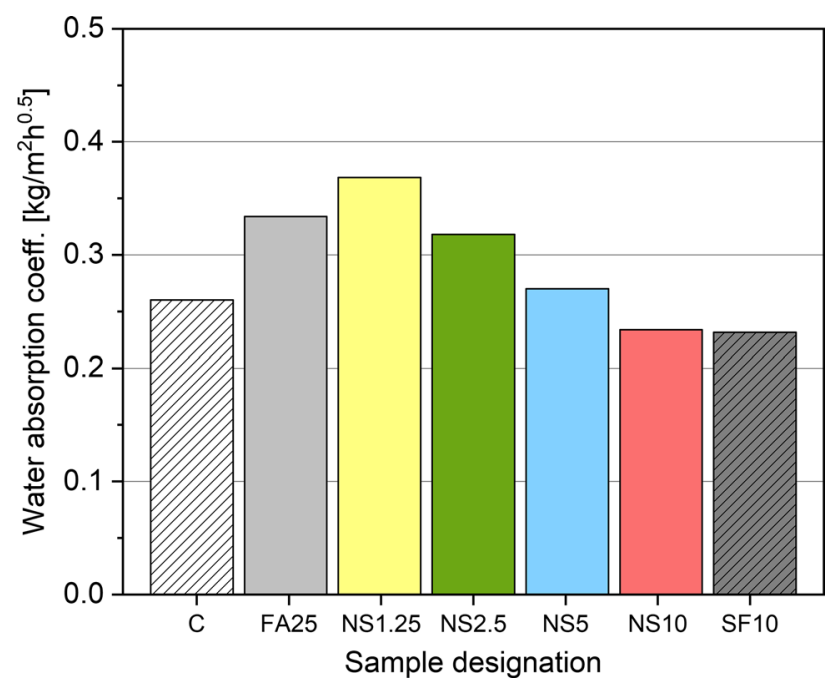

Fig. 11 Foamed concrete water absorption coefficients

\section{Microstructural investigation}

\subsection{Micro-computed tomography}

\subsubsection{Pore characteristics}

The pore characteristics of the foamed concrete specimens, such as porosity and pore size distribution, were examined using the 3D volume images in Fig. 4. The minimum pore size taken into consideration was $31.0 \mu \mathrm{m}$, according to the image resolution. The measured porosity values of the specimens are presented in Table 4 . In this table, the porosity of the $\mathrm{C}$ specimen (reference), showed the highest value among the samples produced. The porosity values of the other samples were between 34 and 36 vol.-\%, which can be considered as almost equal. These results thus indicate that the use of nanosilica, fly ash or silica fume can contribute to porosity reduction and that the degree of influence between the materials is relatively small.

For a more detailed analysis of the pore characteristics, the pore size distributions of the specimens were also evaluated. Figure 12 presents the pore size distributions of the foamed concrete produced. Similarly to the porosity measurements, the minimum pore size considered was $31.0 \mu \mathrm{m}$, in consideration of the voxel size. The figure shows that the general trend of the distribution was almost the same between the samples. However, despite the similarities, some minor differences can be discerned. The pore size

Table 4 Computed porosity using micro-CT

\begin{tabular}{llllll}
\hline Specimen & C & FA25 & NS5 & NS10 & SF10 \\
\hline Porosity (vol.-\%) & 39.25 & 35.27 & 35.71 & 34.79 & 36.81 \\
\hline
\end{tabular}

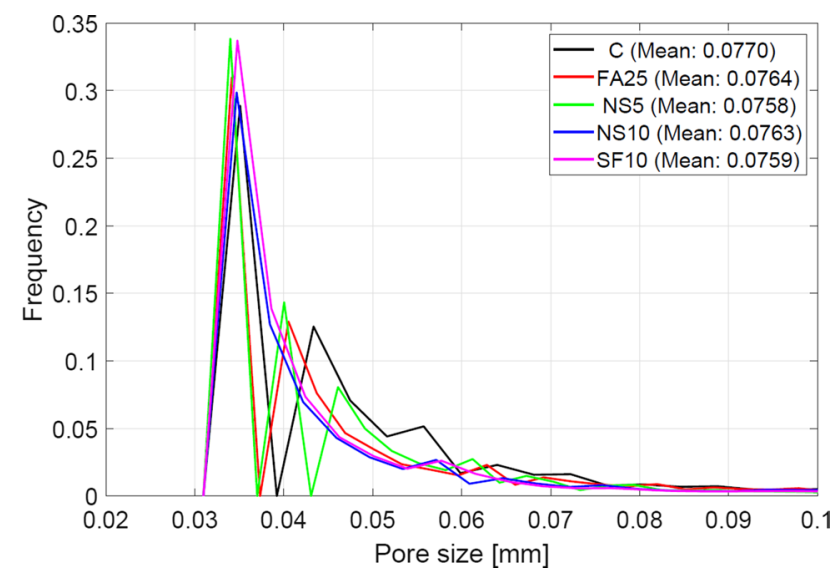

Fig. 12 Pore size distributions and their mean value, of the foamed concrete used 
distribution of $\mathrm{C}$ tended to be relatively evenly distributed between small and large pores, compared to the other specimens. The proportion of pores $>0.05 \mathrm{~mm}$ - which can cause lower compressive strength and thermal conductivity - was higher in the C specimen. In the case of FA25 and NS5, the frequency of the relatively small pores between 0.03 and $0.04 \mathrm{~mm}$ was higher than in the other cases, while NS10 had a lower frequency of pores $>0.05 \mathrm{~mm}$. These may have contributed to the higher compressive strengths of FA25, NS5 and NS10, as compared to the other specimens. As was discussed in regard to the porosity results, although the effect was not significant, the use of NS tends to increase the proportion of small pores, while the frequency of relatively large pores is reduced in specimens without nanosilica.

In addition to the porosity and pore size distributions, a probabilistic method was used to examine the anisotropy of the pores. Foamed concrete contains numerous pores inside the material, with their shape potentially affecting the directional properties of the material [13, 49]. In general, anisotropic pores are not desirable in a material design, since these make it difficult to control and predict material properties. Hence, the use of stabilizers can reduce the anisotropy of the pores produced. Accordingly, appropriate investigations regarding pore shape are required to determine the existence of anisotropic pores.

In this study, a two-point correlation function, $P_{2}$, which is used to characterize the degree of phase clustering, was utilized to ascertain the directional dependency of the pores within the foamed concrete specimens. The two-point correlation function is the probability that any random two points are located in the same phase. The function is widely used to describe the degree of phase clustering of multi-phase materials. A detailed description of the function can be found in $[50,51]$ and a general formulation can be summarized as follows (Eq. 2):

$\lim _{r \rightarrow 0} P_{2}(r, \theta, \varnothing)=f_{v}, \lim _{r \rightarrow \infty} P_{2}(r, \theta, \varnothing)=\left[P_{v}\right]^{2}$

In this formulation, $r$ denotes the distance between the two points, $\theta$ is the angle between the test line and the $z$-axis, is the angle between the projection of the test line on the $x y$ plane and denotes the pore volume fraction [52]. Using this function, the directional size of the pore cluster in the $x, y$, and $z$ directions can be identified and this information can be used to examine the effect of nanosilica on pore shape.

Figure 13 shows the results of the two-point correlation function for the foamed concrete specimens. As can be seen, all the cases taken into consideration showed almost the same trend, indicating isotropic pore shapes in the $x, y$, and $z$ directions, regardless of the addition type. Interestingly, the NS5 and NS10 specimens with nanosilica showed little directional dependency on pore clustering, although they contained relatively less stabilizer than the specimens with cement only, fly ash, or silica fume. This finding denotes

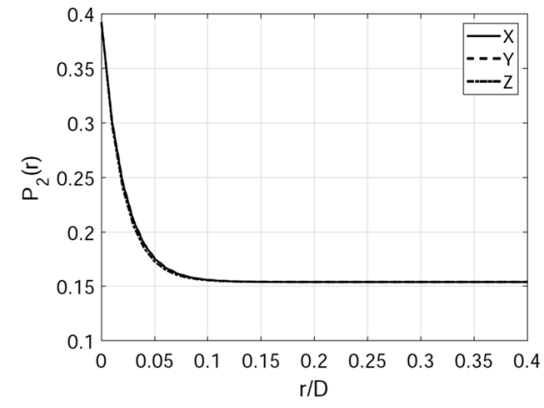

C

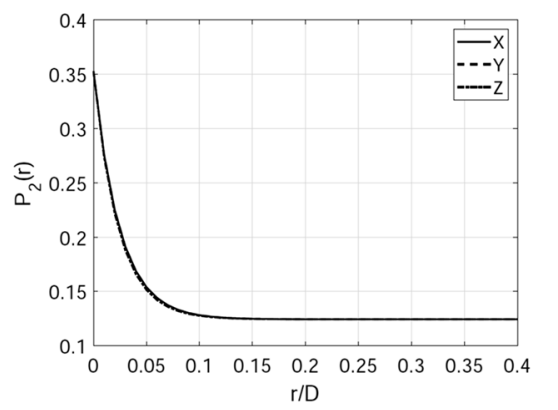

FA25

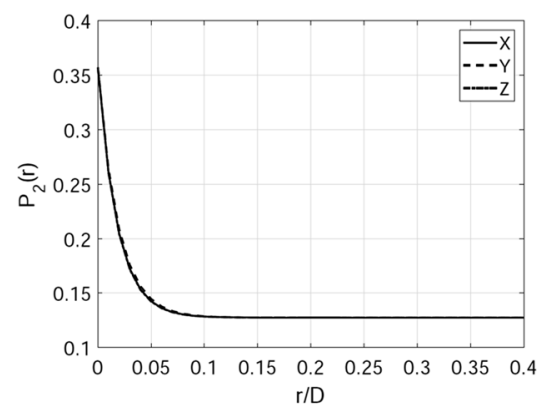

NS5

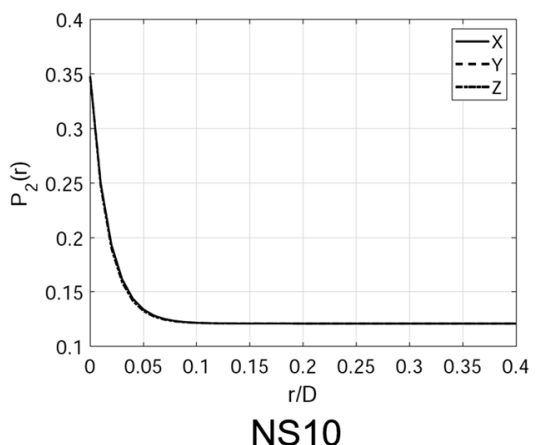

NS10

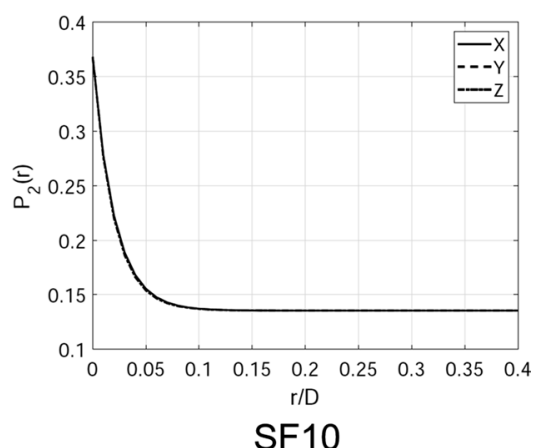

Fig. 13 Two-point correlation function $\left(\mathrm{P}_{2}\right)$ of the specimens used 
that the specimens used included isotropic pores that can be considered as having a stable form and that the addition of NS has a similar effect to a stabilizer, in producing more stable pores.

\subsubsection{Wall thickness investigation}

In addition to the pore characteristics, the wall thicknesses of the solid structures of the foamed concrete specimens were also investigated using the micro-CT images. Detailed information about the pores, including pore radius and the nearest pore, could be determined from the 3D pore images obtained, with this information allowing an evaluation of generalized wall thickness. To compute the wall thickness of associated pores, each pore particle's centroid and radius data is needed, with it being possible to examine solid thickness according to the number of voxels between pores.

Figure 14 shows the generalized wall thickness of the specimens used. In the cases taken into consideration here, the wall thickness distribution was similar between the samples, with a normal pattern distribution. From among all the cases, FA25 had a relatively large portion of thicker solid walls, which was an effect of the specimen's higher density. This in turn contributed to its higher compressive strength. In the specimens with nanosilica, the NS5 specimen contained a solid structure with thicker walls than in the other cases, as confirmed by the higher mean value. The results confirmed that the use of nanosilica and fly ash tends to affect the relatively thicker solid structure of a foamed concrete specimen. Although the general trends affecting the mechanical properties of foamed concrete can be explained with the micro-CT data, complementary investigations with other microstructural approaches, such as SEM, were also needed, since it is difficult to confirm certain converse phenomena only with micro-CT. For instance, the SF10

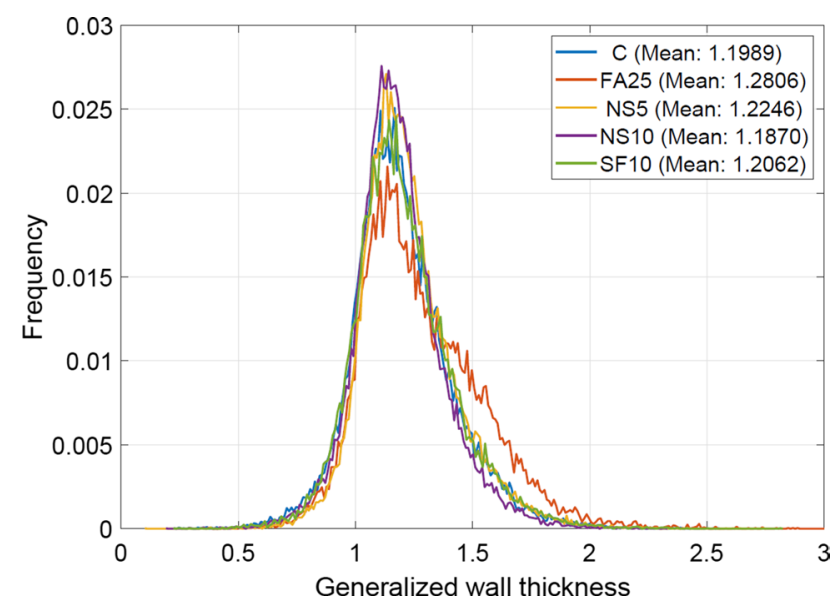

Fig. 14 Wall-thickness distribution and its mean value, of the foamed concrete used specimen had an almost identical wall thickness distribution to NS5, but its compressive strength (Fig. 9) was much lower. This indicates that quantitative investigations using only micro-CT are insufficient for explaining the relevant cases. For this purpose, SEM was also conducted to examine the microstructural features of the foamed specimens.

\subsection{SEM studies}

Micrographs of selected foamed concrete specimens obtained via SEM are presented in Fig. 15. Differences between the specimens can be discerned: the contribution of the solid content in the FA25 concrete was the highest, as a result of the noticeably higher density of this concrete. Moreover, unreacted fly ash particles can be distinguished in the cement matrix (indicated with red arrows). Differences between the NS10 and SF10 specimens can be clearly seen, with a higher solid content in NS10, as compared to SF10. In addition, thicker continuous walls were found in specimen NS10. In contrast, very thin layers between voids were observed more often in specimen SF10 (indicated with a green arrow). This could explain the lower robustness of the foamed concrete solid matrix and thus the lower compressive strength of the SF10 specimen. The difference between NS-modified and SF-modified specimens can be attributed to the state of dispersion and chemical activity of both silica materials. Despite the specific improvements found in specimen SF10, such as a lowered water permeability, the effect of SF was limited when compared to NS. It is widely known that when SF is added in powdered form, its dispersion is limited and thus the material acts as a filler, with a limited chemical activity due to the higher agglomeration of SF, as compared to the highly dispersed, stabilised and pure ( $>99 \%$ of $\mathrm{SiO}_{2}$ ) nanosilica slurry. Therefore, replacement of cement with NS, especially in higher dosages like $5 \mathrm{wt} .-\%$ or $10 \mathrm{wt} .-\%$, facilitates the hydration process and modifies fresh and hardened properties more efficiently than SF. Hence, due to the alteration of the fresh properties in the presence of NS, a more stable concrete mixture with a refined and improved foam structure is produced, which results in ultra-lightweight foamed concrete with improved mechanical and transport properties.

\section{Conclusions}

In general, reducing the density of foamed concrete by increasing foam volume resulted in weak concrete, because of a highly porous microstructure. This investigation focused on the influence of nanosilica addition on the fresh and hardened properties of foamed concrete, with a oven-dry density of around $350 \mathrm{~kg} / \mathrm{m}^{3}$. Based on the experimental and 

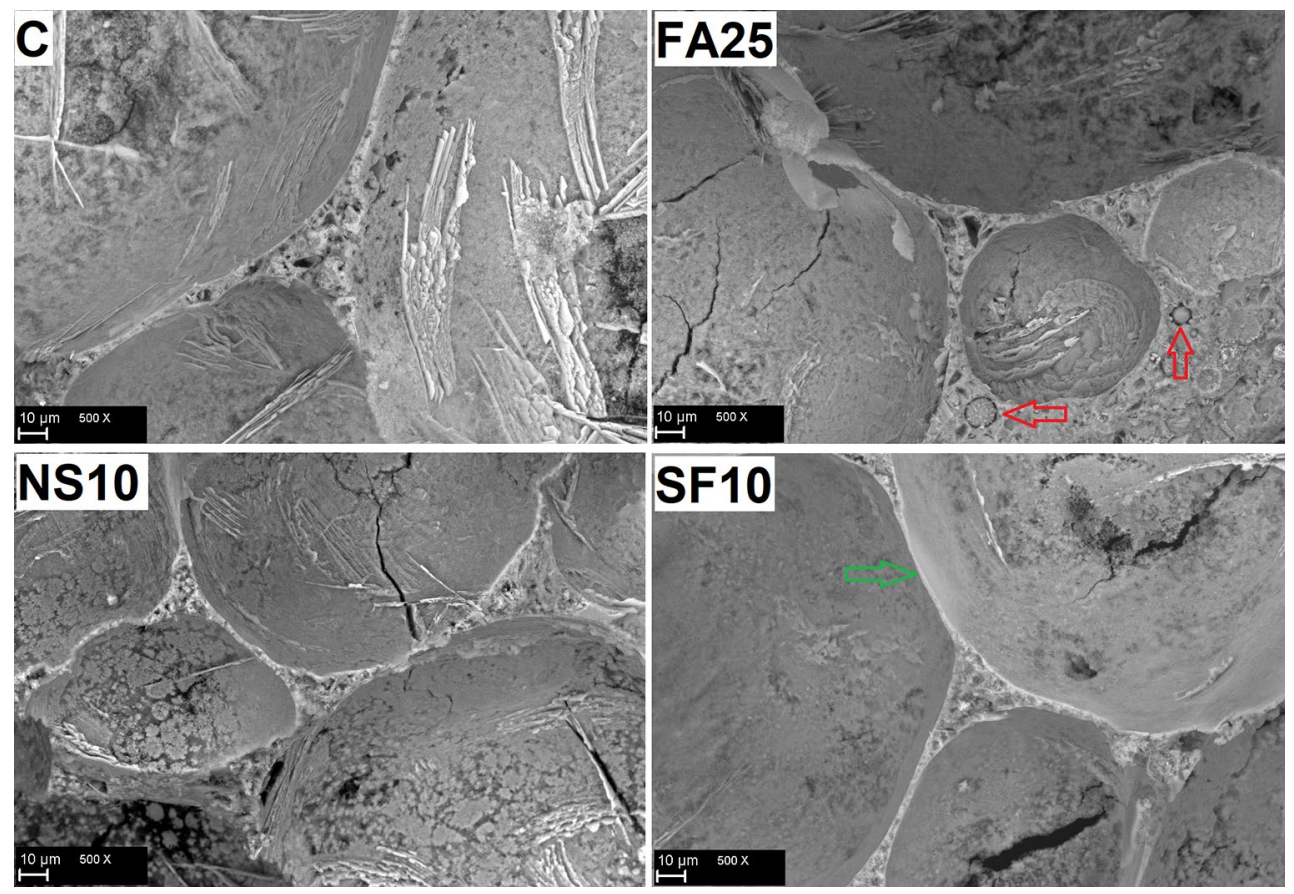

Fig. 15 SEM micrographs of C, FA25, NS5, and SF10 specimens

microstructural results of this study, the following conclusions can be put forward:

1. The incorporation of nanosilica improved the homogeneity of the foamed concrete in the fresh state, since it acted as foam stabilizers. Consequently, the required dosage of viscosity-enhancing admixtures decreased with rising nanosilica content.

2. Micro-CT evaluation confirmed the isotropic distribution of pores inside the foamed concrete, which reflects the role of nanosilica as a foam stabilizing agent.

3. The compressive strength of the foamed concrete, in comparison to control specimen, was significantly improved by $20 \%$ and $25 \%$ when cement was replaced with 5 wt.- $\%$ and 10 wt.- $\%$ of NS. This effect is attributed to physical role in compacting the solid structure and reducing the contact area between foam bubbles.

4. The drying shrinkage of the nanosilica mixes was higher than in the control mix at early ages, while decreasing at $28 \mathrm{~d}$. With increased density, as in the case of fly ash, shrinkage was significantly decreased when specimens contained nanosilica.

5. The total porosity and sorption of the foamed concrete were reduced by the incorporation of nanosilica, because nanosilica refines pores, reduces their size and prevents the merging of foam bubbles.

6. The use of nanosilica increased the wall thickness between foam bubbles and contributed to a denser solid structure, as shown by the micro-CT measurements and
SEM images. The proposed probabilistic approach to determine the pores anisotropy in the specimen can be effectively incorporated as a tool to evaluate the effects of various admixtures on the foam bubbles stability.

As has been shown in this study, foamed concrete with superior thermal insulation characteristics and improved mechanical properties can be developed by incorporating nanosilica. With appropriate chemical admixtures doses, highly stable foamed concrete which satisfies the targeted flowability, can be achieved. Moreover, the inclusion of nanoparticles can significantly improve the performance of foamed concrete, in both fresh and hardened states. Further studies, leading to a better understanding of microstructure and how to reduce drying shrinkage, are needed to confirm the reliability and applicability of low density, ultra-lightweight concrete.

Acknowledgments This project has received funding from the European Union's Horizon 2020 research and innovation program under the Marie Skłodowska-Curie grant agreement No. 841592. This work also supported by the German Egyptian Program for Scientific Exchange and Excellent Development (GE-SEED, DAAD and STDF). The authors would like to express their appreciation to Paul H. Kamm (Helmholtz Centre Berlin) for his assistance in micro-CT imaging and Christian Lehmann (TU Berlin) for his support in SEM measurement.

Funding Open Access funding enabled and organized by Projekt DEAL. 


\section{Declarations}

Conflict of interest On behalf of all authors, the corresponding author states that there is no conflict of interest.

Open Access This article is licensed under a Creative Commons Attribution 4.0 International License, which permits use, sharing, adaptation, distribution and reproduction in any medium or format, as long as you give appropriate credit to the original author(s) and the source, provide a link to the Creative Commons licence, and indicate if changes were made. The images or other third party material in this article are included in the article's Creative Commons licence, unless indicated otherwise in a credit line to the material. If material is not included in the article's Creative Commons licence and your intended use is not permitted by statutory regulation or exceeds the permitted use, you will need to obtain permission directly from the copyright holder. To view a copy of this licence, visit http://creativecommons.org/licenses/by/4.0/.

\section{References}

1. Nguyen TT, Bui HH, Ngo TD, Nguyen GD. Experimental and numerical investigation of influence of air-voids on the compressive behavior of foamed concrete. Mater Des. 2017;130:103-19. https://doi.org/10.1016/j.matdes.2017.05.054.

2. She W, Yi Du, Miao C, Liu J, Zhao G, Jiang J, Zjang Y. Application of organic-and nanoparticle-modified foams in foamed concrete: reinforcement and stabilization mechanisms. Cem Concr Res. 2018;106:12-22. https://doi.org/10.1016/j.cemconres.2018. 01.020 .

3. E.K. Kunhanandan Nambiar, K. Ramamurthy, "Air-void characterisation of foam concrete", Cement and Concrete Resaearch 37 (2007) 221-230. Doi: https://doi.org/10.1016/j.cemconres.2006. 10.009

4. Gong J, Zhang W. The effects of pozzolanic powder on foam concrete pore structure and frost resistance. Constr Build Mater. 2019;208:135-43. https://doi.org/10.1016/j.conbuildmat.2019.02. 021 .

5. Chung S-Y. Mohamed Abd Elrahman, Ji-Su Kim, Tong-Seok Han, Dietmar Stephan, Pawel Sikora, "Comparison of lightweight aggregate and foamed concrete with the same density level using image-based characterizations." Constr Build Mater. 2019;211:988-99. https://doi.org/10.1016/j.conbuildmat.2019.03. 270.

6. Kuzielova E, Pach L, Palou M. Effect of activated foaming agent on the foam concrete properties. Constr Build Mater. 2016;125:998-1004. https://doi.org/10.1016/j.conbuildmat.2016. 08.122 .

7. Falliano D, De Domenico D, Sciarrone A, Ricciardi L, Restuccia L, Tulliani JMC, Gugliandolo E. Fracture behavior of lightweight foamed concrete: The crucial role of curing conditions. Theoret Appl Fract Mech. 2019;103:102297. https://doi.org/10.1016/j. tafmec.2019.102297.

8. Mugahed Amran YH, Farzadnia N, Abang Ali AA Properties and applications of foamed concrete; a review. Construction Building Materials 101 (2015), 990-1005. Doi:https://doi.org/10.1016/j. conbuildmat.2015.10.112

9. Kim J-S, Chung S-Y, Lehmann C, Stephan D, Han T-S. Mohamed Abd Elrahman, "Modelling of multiple phase solid microstructures and prediction of mechanical behaviors of foamed concrete." Constr Build Mater. 2020;248:118637. https://doi.org/10.1016/j. conbuildmat.2020.118637.
10. Chung S-Y, Kim J-S, Han T-S, Stephan D, Abd Elrahman M. Investigation of phase composition and microstructure of foamed cement paste with different supplementary cementing materials. Cement Concr Compos. 2020;109:103560. https://doi.org/10. 1016/j.cemconcomp.2020.103560.

11. Kuzielová E, Žemlička M, Bača L, Pach L. Preparation of lightweight foam concretes with bulk density less than $200 \mathrm{~kg} / \mathrm{m} 3$. Cement Wapno Beton. 2018;5:369-78.

12. Chung S-Y, Lehmann C, Abd Elrahman M, Stephan D. Microstructural characterization of foamed concrete with different densities using microscopic techniques. Cement Wapno Beton. 2018;3:216-25.

13. Chung S-Y, Lehmann C, Abd Elrahman M, Stephan D. Pore characteristics and their effects on the material properties of foamed concrete evaluated using micro-CT images and numerical approaches. Appl Sci. 2017;7:550. https://doi.org/10.3390/ app7060550.

14. Elrahman MA, El Madawy ME, Chung S-Y, Majer S, Youssf O, Sikora P. An investigation of themechanical and physical characteristics of cement paste incorporating different air entraining agentsusing $\mathrm{x}$-ray micro-computed tomography. Curr ComputAided Drug Des. 2020;10:23. https://doi.org/10.3390/cryst 10010023.

15. Zhihua P, Hengzhi Li, Weiqing L. Preparation and characterization of super low density foamed concrete from Portland cement and admixtures. Constr Build Mater. 2014;72:256-61. https:// doi.org/10.1016/j.conbuildmat.2014.08.078.

16. Falliano D, De Domenico D, Ricciardi G, Gugliandolo E. Compressive and flexural strength of fiber-reinforced foamed concrete: effect of fiber content, curing conditions and dry density. Constr Build Mater. 2019;198:479-93. https://doi.org/10. 1016/j.conbuildmat.2018.11.197.

17. Falliano D, De Domenico D, Ricciardi G, Gugliandolo E. Experimental investigation on the compressive strength of foamed concrete: effect of curing conditions, cement type, foaming agent and dry density. Constr Build Mater. 2018;165:735-49. https://doi.org/10.1016/j.conbuildmat.2017.12.241.

18. Huang $\mathrm{Z}$, Zhang $\mathrm{T}$, Wen $\mathrm{Z}$. Proportioning and characterization of Portland cement-based ultra-lightweight foam concretes. Constr Build Mater. 2015;79:390-6. https://doi.org/10.1016/j. conbuildmat.2015.01.051.

19. Roderick JM, Zheng Li, Ozlutas K. High-volume, ultra-low-density fly ash foamed concrete. Mag Concr Res. 2019;69:1146-56. https://doi.org/10.1680/jmacr.17.00063.

20. Hilal AA, Thom NH, Dawson AR. On void structure and strength of foamed concrete made without/with additives. Construction Building Materials. 2015;875:157-64. https://doi.org/ 10.1016/j.conbuildmat.2015.03.093.

21. Xin W, Huang J, Dai S, Ma B, Jiang Qi. Investigation of silica fume as foam cell stabiliyer for foamed concrete. Constr Build Mater. 2020;237:117514. https://doi.org/10.1016/j.conbuildmat. 2019.117514

22. Roderick JM, McCarthy A. Preliminary views on the potential of foamed concrete as a structural material. Mag Concrete Res. 2005;57:21-31. https://doi.org/10.1680/macr.2005.57.1.21.

23. Roslan AF, Awang H, Mydin MAO (2013) Effects of various additives on drying shrinkage, compressive and flexural strength of lightweight foamed concrete (LFC). Advanced Materials Res 626:594-604. Doi: https://doi.org/10.4028/www.scientific.net/ AMR.626.594

24. Chindaprasirt P, Rattanasak U. Shrinkage behavior of structural foam lightweight concrete containing glycol compounds and fly ash. Mater Des. 2011;32:723-7. https://doi.org/10.1016/j. matdes.2010.07.036.

25. Raj A, Sathyan D, Mini KM. Physical and functional characteristics of foamed concrete: a review. Construction Building 
Materials. 2019;221:787-99. https://doi.org/10.1016/j.conbu ildmat.2019.06.052.

26. Chindaprasirt P, Rukzon S, Sirivivatnanon V. Resistance to chloride penetration of blended Portland cement mortar containing palm oil fuel ash, rice husk ash and fly ash. Constr Build Mater. 2008;22:932-8. https://doi.org/10.1016/j.conbuildmat. 2006.12.001.

27. Chao Sun Yu, Zhu JG, Zhang Y, Sun G. Effects of foaming agent type on the workability, drying shrinkage, frost resistance and pore distribution of foamed concrete. Constr Build Mater. 2018;186:833-9. https://doi.org/10.1016/j.conbuildmat.2018. 08.019 .

28. Ramamurthy K, Nambiar EK, Ranjani GI. A classification of studies on properties of foam concrete. Cement Concrete Composites. 2009;31:388-96. https://doi.org/10.1016/j.cemco ncomp.2009.04.006.

29. Mohamed AE, Madawy ME, Chung S-Y, Sikora P, Stephan D. Preparation and characterization of ultra lightweight foamed concrete incorporating lightweight aggregates. Appl Sci. 2019;9:1447. https://doi.org/10.3390/app9071447.

30. Mohamed AE, Chung S-Y, Sikora P, Rucinska T, Stephan D. Influence of nanosilica on mechanical properties, sorptivity and microstructure of lightweight concrete. Materials. 2019;12:3078. https://doi.org/10.3390/ma12193078.

31. Zhang J, Liu X. Research on the influence of carbon nanotubes (CNTs) on compressive strength and air-void structure of ultralight foamed concrete. Mech Adv Mater Struct. 2019;26:2009-16. https://doi.org/10.1080/15376494.2018.1475583.

32. Luo J, Hou D, Li Q, Caifeng Wu, Zhang C. Comprehensive performances of carbon nanotube reinforced foam concrete with tetraethyl orthosilicate impregnation. Constr Build Mater. 2017;131:512-6. https://doi.org/10.1016/j.conbuildmat.2016.11. 105 .

33. Zhang J, Liu X. Dispersion performance of carbon nanotubes on ultra-light foamed concrete. Processes. 2018;6:194. https://doi. org/10.3390/pr6100194.

34. Li Z, Gong J, Sen Du, Jianlin Wu, Li J, Hoffman D, Shi X. Nanomontmorillonite modified foamed paste with a high volume fly ash binder. RSC Adv. 2017;16:9803-12. https://doi.org/10.1039/ C6RA26968K

35. Krämer C, Schauerte M, Kowald TL, Trettin RHF. Threephase-foams for foam concrete application. Mater Charact. 2015;102:173-9. https://doi.org/10.1016/j.matchar.2015.03.004.

36. Sikora P, Cendrowski K, Abd Elrahman M, Chung S-Y, Mijowska E, Stephan D The effects of seawater on the hydration, microstructure and strength development of Portland cement pastes incorporating colloidal silica. Appl Nanosci (2019). https://doi. org/https://doi.org/10.1007/s13204-019-00993-8

37. Mohamed AE, Chung S-Y. Effect of different expanded aggregates on the properties of lightweight concrete. Mag Concrete Res. 2018;71:95-107. https://doi.org/10.1680/jmacr.17.00465.

38. Bossa N, Chaurand P, Vicente J, Borschneck D, Levard C, Chariol OA, Rose J. Micro- and nano-X-ray computed-tomography: a step forward in the characterization of the pore-network of a leached cement paste. Cem Concr Res. 2015;67:138-47. https://doi.org/ 10.1016/j.cemconres.2014.08.007.

39. Yang Z, Ren W, Sharma R, et al. In-situ X-ray computed tomography characterisation of $3 \mathrm{~d}$ fracture evolution and image-based numerical homogenisation of concrete. Cement Concr Compos. 2017;75:74-83. https://doi.org/10.1016/j.cemconcomp.2016.10. 001.

40. Chung S-Y, Kim J-S, Stephan D, Han T-S. Overview of the use of micro-computed tomography (micro-CT) to investigate the relation between the material characteristics and properties of cementbased materials. Constr Build Mater. 2019;229:116843. https:// doi.org/10.1016/j.conbuildmat.2019.116843.

41. Moreno FG, Fromme M, Banhart J. Real-time X-ray radioscopy on metallic foams using a compact micro-focus source. Adv Eng Mater. 2004;6:416-20. https://doi.org/10.1002/adem.200405143.

42. Otsu N. A threshold selection method from gray-level histograms. IEEE Trans Syst Man Cybern. 1979;9:62-6.

43. Huang D-Y, Wang C-H. Optimal multi-level thresholding using a two-stage Otsu optimization approach. Pattern Recogn Lett. 2009;30:275-84. https://doi.org/10.1016/j.patrec.2008.10.003.

44. Land G, Stephan D. The influence of nano-silica on the hydration of ordinary Portland cement. J Mater Sci. 2012;47:1011-7. https:// doi.org/10.1007/s10853-011-5881-1.

45. Sikora P, Lootens D, Liard M, Stephan D. The effects of seawater and nanosilica on the performance of blended cements and composites. Appl Nanosci. 2020. https://doi.org/10.1007/ s13204-020-01328-8.

46. Nambiar EK, Ramamurthy K. Influence of filler type on the properties of foam concrete. Cement Concr Compos. 2006;28:475-80. https://doi.org/10.1016/j.cemconcomp.2005.12.001.

47. Gokce HS, Hatungimana D, Ramyar K. Effect of fly ash and silica fume on hardened properties of foam concrete. Construction Building Materials. 2019;194:1-11. https://doi.org/10.1016/j. conbuildmat.2018.11.036.

48. Nambiar EK, Ramamurthy K. Sorption characteristics of foam concrete. Cem Concr Res. 2007;37(9):1341-7. https://doi.org/10. 1016/j.cemconres.2007.05.010.

49. Kearsley EP, Wainwright PJ. The effect of porosity on the strength of foamed concrete. Cem Concr Res. 2002;32:233-9. https://doi. org/10.1016/S0008-8846(01)00665-2.

50. Tewari A, Gokhale AM, Spowart JE, Miracle DB. Quantitative characterization of spatial clustering in three-dimensional microstructures using two-point correlation functions. Acta Materials. 2004;52:307-19. https://doi.org/10.1016/j.actamat.2003.09.016.

51. Gokhale A, Tewari A, Garmestani H. Constraints on microstructural two-point correlation functions. Scripta Materials. 2005;53:989-93. https://doi.org/10.1016/j.scriptamat.2005.06. 013.

52. Chung S-Y, Elrahman MA, Stephan D, Kamm PH. Investigation of characteristics and responses of insulating cement paste specimens with Aer solids using X-ray micro-computed tomography. Constr Build Mater. 2016;118:204-15. https://doi.org/10.1016/j. conbuildmat.2016.04.159.

Publisher's Note Springer Nature remains neutral with regard to jurisdictional claims in published maps and institutional affiliations. 